\title{
COVID-19 and Diabetes Mellitus: A Complex Interplay
}

\author{
Gopala Koneru' $^{1 *}$ (D), Hager H. Sayed ${ }^{2}$ (D), Nayera A. Abd-elhamed² (D), Nouran \\ Elsedfy $^{2}(D)$, Amira H. Mohamed ${ }^{2}$ (D), Hania A. Abdellatif ${ }^{2}$ (D), Fatmaalzharaa F. \\ Mohamed $^{2}$ (D), Esraa H. Bahnasawy ${ }^{2}$ (D) Nayera K. Mousa ${ }^{2}$ (D) Aml Eisa² (D), \\ Esraa A. Elshenawy ${ }^{(D)}$, Yassmin Z. Basheer ${ }^{2}$ (D) Esraa H. Sayed² (D), \\ Farah F. Mohamed ${ }^{2}$ (D), Walaa R. Ali² (D), Hadir A. Soliman² (D), \\ Ashrakt A. Eltabary² (D), Noorhan M. Sayed ${ }^{2}$ D , Nourhan H. Nasr ${ }^{2}$ (D), \\ Nour S. Khairallah' ${ }^{2}$ a and Helal F. Hetta ${ }^{3,4 *}$ (D) \\ ${ }^{1}$ Department of Medicine, Division of Gastroenterology and Hepatology, Rutger New Jersey \\ Medical School, Rutgers University, New Jersey 07103, USA. \\ ${ }^{2}$ House Officer, Faculty of Medicine, Assiut University, Assiut 71515, Egypt. \\ ${ }^{3}$ Department of Medical Microbiology and Immunology, Faculty of Medicine, \\ Assiut University, Assiut 71515, Egypt. \\ ${ }^{4}$ Department of Internal Medicine, University of Cincinnati, College of Medicine, Cincinnati, OH 45267, USA.
}

\begin{abstract}
COVID-19 pandemic, which caused by the newly emerged severe acute respiratory syndrome coronavirus-2 (SARS- CoV-2), puts the entire world in an unprecedented crisis, leaving behind huge human losses and serious socio-economical damages. The clinical spectrum of COVID-19 varies from asymptomatic to multi-organ manifestations. Diabetes mellitus (DM) is a chronic inflammatory condition, which associated with metabolic and vascular abnormalities, increases the risk for SARSCoV-2 infection, severity and mortality. Due to global prevalence, DM effect on COVID-19 outcomes as well as the potential mechanisms by which DM modulates the host-viral interactions and host-immune responses are discussed in this review. This review also highlights the effects of anti-diabetic drugs on treatment of SARS-CoV-2 infection and vice versa.
\end{abstract}

Keywords: COVID-19, diabetes, risk factor, cytokines

*Correspondence: Gk489@njms.rutgers.edu; helal.hetta@uc.edu
(Received: January 08, 2021; accepted: March 16, 2021)
Citation: Koneru G, Sayed HH, Abd-elhamed NA, et al. COVID-19 and Diabetes mellitus: A Complex Interplay. J Pure Appl
Microbiol. 2021;15(2):512-523. doi: 10.22207/JPAM.15.2.16
(C) The Author(s) 2021. Open Access. This article is distributed under the terms of the Creative Commons Attribution 4.0 International License which
permits unrestricted use, sharing, distribution, and reproduction in any medium, provided you give appropriate credit to the original author(s) and
the source, provide a link to the Creative Commons license, and indicate if changes were made. 


\section{INTRODUCTION}

Late 2019, a novel coronavirus (CoV), known as severe acute respiratory syndrome coronavirus-2 (SARS-CoV-2, previously 2019$\mathrm{nCoV}$ ), has emerged in Wuhan, Hubei province, China. This virus has spread rapidly within and between other countries, and causing coronavirus disease-2019 (COVID-19). On March 2020, World Health Organization (WHO) declared COVID-19 outbreak as a global pandemic. COVID-19 is associated with a wide spectrum of symptoms such cough, fever, headache, myalgia, loss of taste and smell, respiratory problems and in severe cases, it may cause respiratory failure and death ${ }^{1-8}$.

In addition to older ages, certain chronic medical conditions such as hypertension, diabetes, and cardiovascular diseases increase the risk for severe SARS-CoV-2 infection ${ }^{9,10}$. It is unsurprising that diabetic patients are more likely to be infected and have a significantly high risk for hospitalization and mortality from COVID-19. Similar increased risk for other coronaviral infections such as severe acute respiratory syndrome (SARS) in 2003 and Middle East respiratory syndrome (MERS) in 2012 has been reported in diabetic patients ${ }^{11,12}$.

Considering global prevalence of diabetes mellitus (DM) (about 422 million worldwide, WHO) and high transmission rate of SARS-CoV-2, these two pandemics cause significant mortality and morbidity. So, it is not advised to underestimate COVID-19 infection in diabetic patients even if the initial symptoms are mild. In this review, medical data have been collected to better understand the relation between DM and COVID-19 infection and severity.

\section{Coronaviruses}

Coronaviruses (CoVs) are enveloped positive-sense, single-stranded RNA viruses belonging to Coronaviridae family ${ }^{13-15}$. Most known human CoVs are associated with self-limiting mild diseases. However, three beta-CoVs, such as SARS-CoV, Middle East respiratory syndrome coronavirus (MERS-CoV) and novel SARS-CoV-2, resulted in major outbreaks with life threatening effects $^{16,17}$. Despite phylogenetic similarity (79.5\%), SARS-CoV-2 has lower mortality rate but higher transmission rate than SARS-CoVs ${ }^{18}$. The genome of SARS-CoV-2 contains several open reading frames $(\mathrm{ORFs})^{19,20}$. Structural proteins of CoVs are spike (S), envelope (E), membrane (M), and nucleocapsids (N) proteins (Fig. 1) ${ }^{21-23}$. S protein, which is expressed on virus surface, is responsible for recognition and binding to host cell receptors and it has two conserved domains S1 and S2 ${ }^{15}$.

Genomic analysis revealed that sites of receptor binding domains (RBDs) of SARS-CoV-2 bind angiotensin-converting enzyme 2 (ACE2) receptor, which is the same human cell receptor

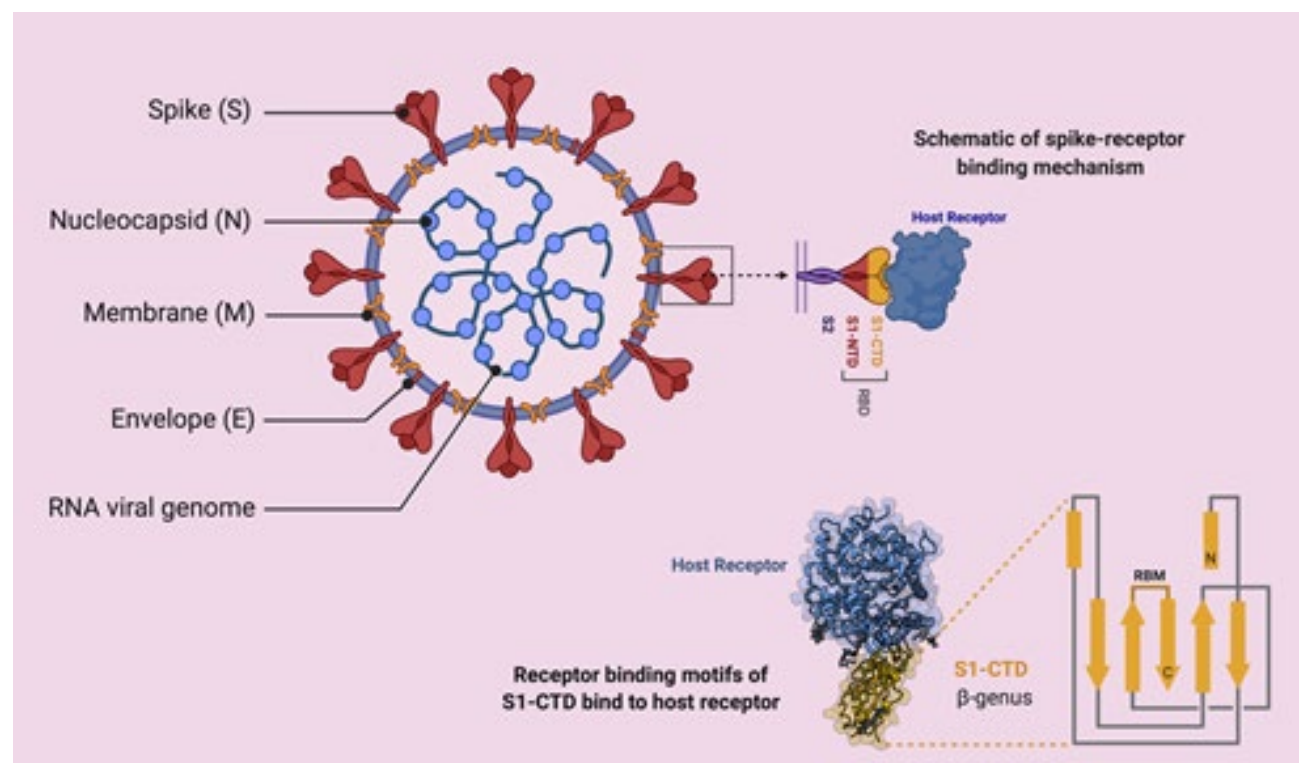

Fig. 1. Coronavirus structure and spike-receptor binding (Created by Biorender.com). 
for SARS-CoV but with higher receptor binding affinity (10- to 20- fold $)^{24,25}$. Unfortunately, ACE2 receptors are widely distributed on plasma membrane of host cells of many tissues such as lungs, heart, kidney and liver ${ }^{18,26-30}$. This explains the multi-organ dysfunction including acute respiratory distress syndrome (ARDS), acute myocardial and kidney injury ${ }^{31,32}$. It was found that injury of these organs was much more serious in diabetes compared to those without diabetes ${ }^{33}$. Furthermore, immunestaining of ACE2 revealed significant expression of ACE2 protein in pancreatic islets, which also explains that SARS-CoV-2 may result in diabetes via damaging the pancreatic islets $^{34,35}$. Nucleocapsids protein (N) in SARS-CoV has the ability of neutralizing the host's immune system by acting as an antagonist to IFN-g. If this ability proved to be absent in SARS-CoV-2, it would present an explanation for the lower mortality rate of the novel $\mathrm{CoV}^{36}$.

\section{Clinical characteristics of COVID-19}

The clinical spectrum of COVID-19 varies from asymptomatic to multi-organ manifestations. The symptoms start as mild flu-like symptoms, and may rapidly develop severe symptoms. The different symptoms reported with COVID-19 include cough, fever, headache, myalgia, loss of taste and smell, shortness of breath, sore throat, vomiting and diarrhea ${ }^{37-39}$. However, severe cases can develop signs and symptoms of acute respiratory distress syndrome (ARDS), respiratory failure and failure of other organs. Severe cases require supportive treatment and admission to intensive care unit ${ }^{39-41}$.

\section{Diabetes as a risk factor for COVID-19}

Diabetes, which is a worldwide leading cause of morbidity and mortality, has a high potential risk for viral infections, mainly due to defects of innate and adaptive immunity (Fig. 2).

Some potential mechanisms, which increase diabetic patients' susceptibility to infection, are discussed in this review. ACE2, as the receptor responsible for SARS-CoV-2 binding and entry, has an increased expression level in DM (Fig. 3) ${ }^{42}$. Additionally, Fernandez et al. ${ }^{43}$ found that a cellular protease (furin), which plays a role in virus entry through cleavage of S1 and S2, is high in DM. Viral clearance is based mainly on T-cell action, natural killer cell activity and complement action, which are disturbed in diabetes ${ }^{44}$. Several studies reported a significant relation between DM and infection severity of different CoVs such as SARS-CoVs, MERS-CoVs and SARSCoV- $2^{45-50}$. Diabetes, as a chronic inflammatory

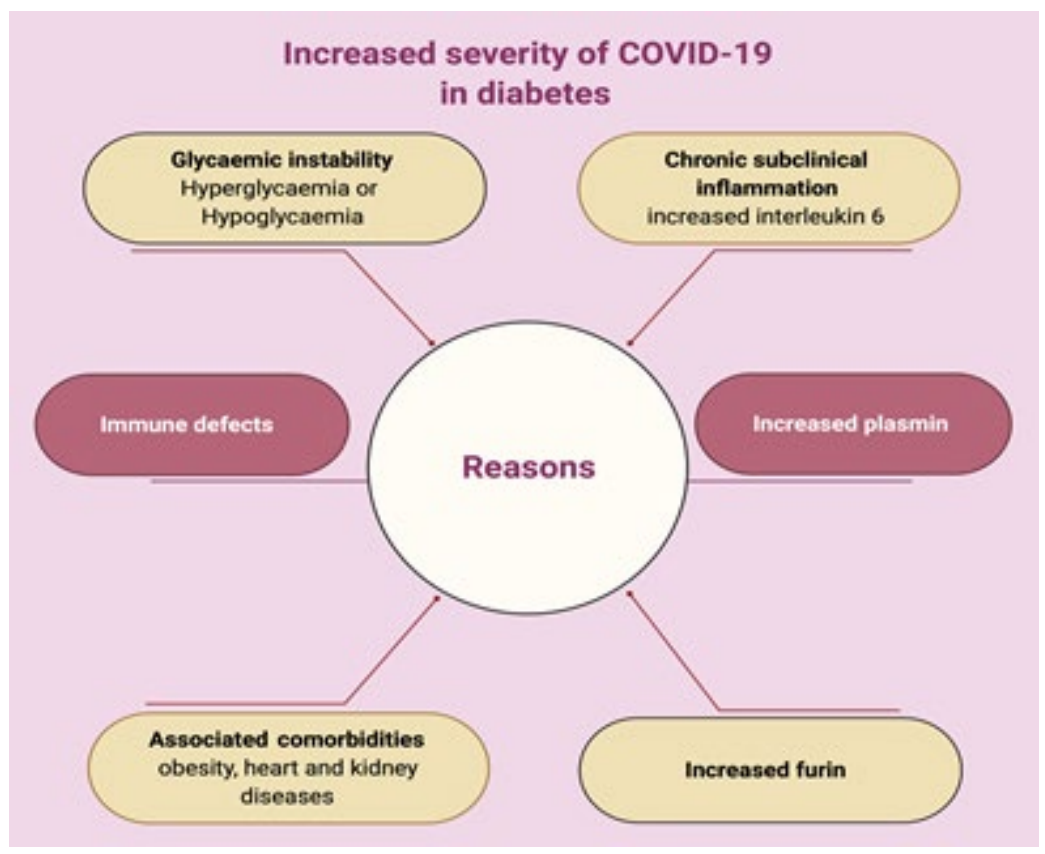

Fig. 2. Different reasons of increased severity of COVID-19 in diabetes (Created by Biorender.com). 
condition associated with metabolic and vascular abnormalities, affects the body response to pathogens $\mathrm{s}^{51-54}$. Accordingly, within hospitalized COVID-19 patients, diabetic patients are overrepresented with higher mortality rate reaching $50 \%{ }^{41,47,55}$. In diabetic patients, SARS-CoV-2 triggers higher stress conditions, inducing hyperglycemic hormones (glucocorticoids and catecholamines) and elevating blood sugar levels ${ }^{46}$. Uncontrolled diabetes is associated with inhibited lymphocyte proliferative response and impaired function of monocyte/macrophage and neutrophil (Fig. 3). A study on diabetic mice showed prolonged severe course of COVID-19 infection with delayed recovery and further histological study showed fewer levels of monocyte/macrophages and CD4+ T-cells, CD8+ T-cells, lower chemokine 10 expression, lower level of tumor necrosis factor alpha, IL-6 and IL-12b, but higher levels of IL-7 $\mathrm{a}^{55}$. In DM, an inflammatory storm forms after SARS-CoV-2 infection due to the delay in initiation of adaptive immunity, resulting in respiratory failure and rapid deterioration of other organs (Fig. $3)^{33}$. Additionally, in diabetes there is a high level of plasminogen, which increases the virus virulence ${ }^{56}$. Further, the inflammation biomarkers (such as IL-6, serum ferritin and coagulation index, C-reactive protein and D-dimer) were significantly higher in $\mathrm{DM}^{57-60}$. Diabetes-associated comorbidities such as hypertension, kidney and heart diseases play a role in worsening the prognosis. Additionally, diabetes can result in structural lung changes, leading to impaired gas exchange and the pulmonary microvasculature may be well prepared to COVID-19 infection ${ }^{48,61}$. A study has been reported by Kohio et al. ${ }^{62}$, showing that the high sugar level significantly increases viral replication.

The possible cause of severe hypoxemia in spite of well-preserved lung mechanics that occur with COVID-19 infection is the endothelial damage and pulmonary micro vascular thrombosis. DM affects innate immunity, leading to endothelial dysfunction and deregulation of V. D, fibrinolysis and anti-aggravations, this results in macrovascular diseases or even micro vascular diseases leading to pulmonary complications (diabetic lung) ${ }^{63}$. Glycemic instability either hyperglycemia or even hypoglycemia may increase the severity of COVID-19 ${ }^{64}$. Another link between COVID-19 and DM is down regulation of ACE2, leading to severe lung injury ${ }^{65}$. Severe cases and dead patients of COVID-19 show increase level of TYG (insulin resistance marker).

Interestingly, hospitalized COVID-19 patients with controlled levels of blood sugar showed lower mortality rates than those with poorly controlled blood sugar levels ${ }^{47}$.

\section{Type 1 DM (T1D) versus type 2 DM (T2D)}

Type 1 DM represents $10 \%$ of diabetic patients and it is mediated by autoimmune

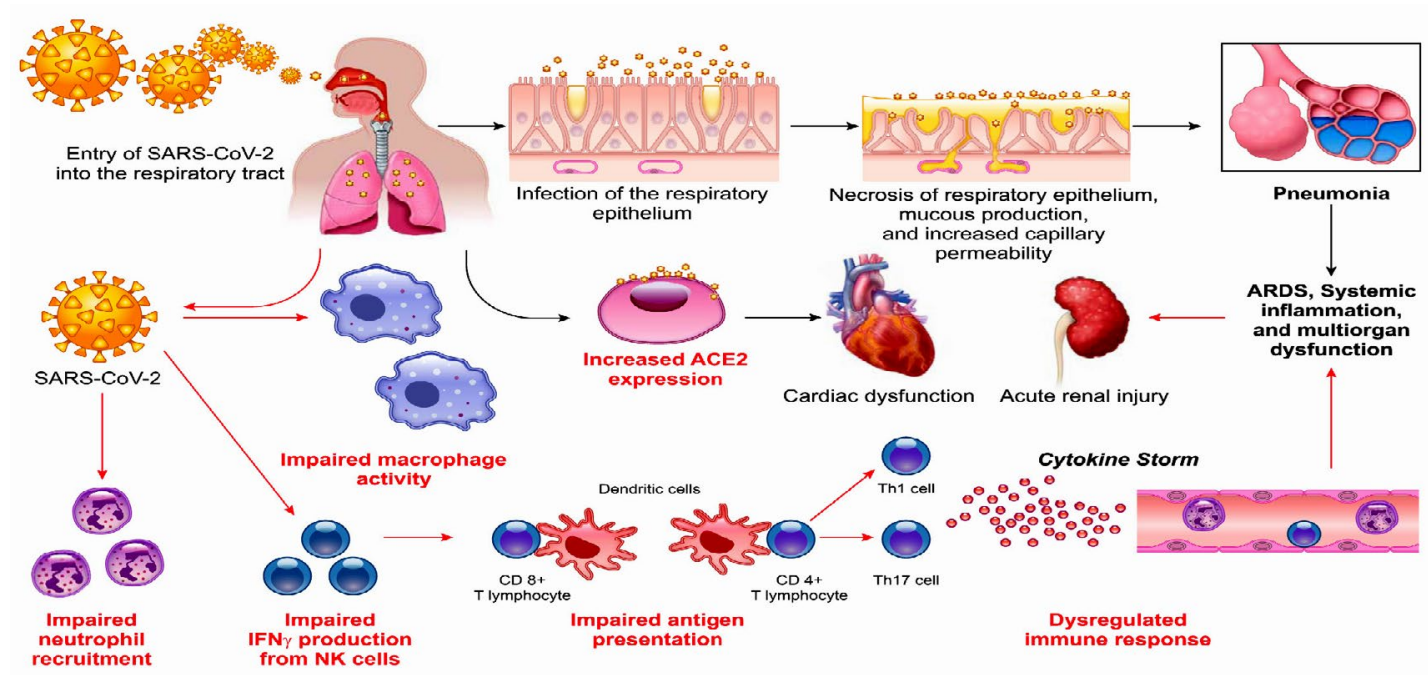

Fig. 3. Potential mechanisms that increase susceptibility of diabetic patients for COVID-19 infection (Adapted from Muniyappa R and Gubbi S ${ }^{12}$ ).

Journal of Pure and Applied Microbiology 
reaction to proteins of pancreatic beta cells. $\mathrm{T} 2 \mathrm{D}$ is due to combination of some genetic and environmental factors ${ }^{66-69}$. Both Type 1 and 2 increase the risk for SARS-CoV-2 infection and related complications. Human immunity against CoVs depends mainly on the balance between $T$ helper 1 (Th1) and Thelper 2 (Th2) immunity. Th1 immunity, which acts mainly against intracellular pathogens such as SARS-CoV-2, mediated by T lymphocyte and modulated by IL-6 and interferon gamma. T1D shows imbalance between Th1 and Th2 immunity in favor of Th1, which may make type 1 diabetic patients at a lower risk for COVID -19 infections ${ }^{70}$.

\section{COVID-19 patients and microangiopathy in hyperglycemia}

Main reason of morbidity and mortality in diabetes is the vascular complications, which occur due to systemic metabolic disorders (hyperglycemia and dyslipidemia) and tissue reactions to toxic metabolites. ${ }^{71}$ Control of blood sugar can delay onset of diabetic microvascular complications and slows down progression ${ }^{72}$. High blood sugar level starts its injurious effects by raising the amount of its metabolites in vascular cells; this can lead to certain changes in its functions. Additionally, high glucose metabolism can generate specific toxic products, which can mediate the specific toxic actions of high blood sugar level and lead to microvascular injuries. The specific pathologic outcomes are modulated by the needs of various tissues, significance of the various functions that are changed by high blood glucose level, and the protective reactions made by each tissue. The main microvascular injuries include retinopathy, nephropathy, and neuropathy. Also, brain, skin, cardiac muscle and other tissues are involved ${ }^{72}$.

\section{COVID-19 and pulmonary microangiopathy}

COVID-19 caused pulmonary complications, which is characterized by dissociation between severity of hypoxemia and maintenance of good respiratory mechanics ${ }^{73}$. Coagulation dysfunction is common in intense COVID-19 and thrombogenic microvascular injury appeared in fatal cases ${ }^{63,74}$. Endothelial damage and pulmonary microvascular thrombosis currently indicate clinical severity of COVID-19 ${ }^{73,74}$. SARS-CoV-2 enters into endothelial cells through binding of viral entry protein (S protein)

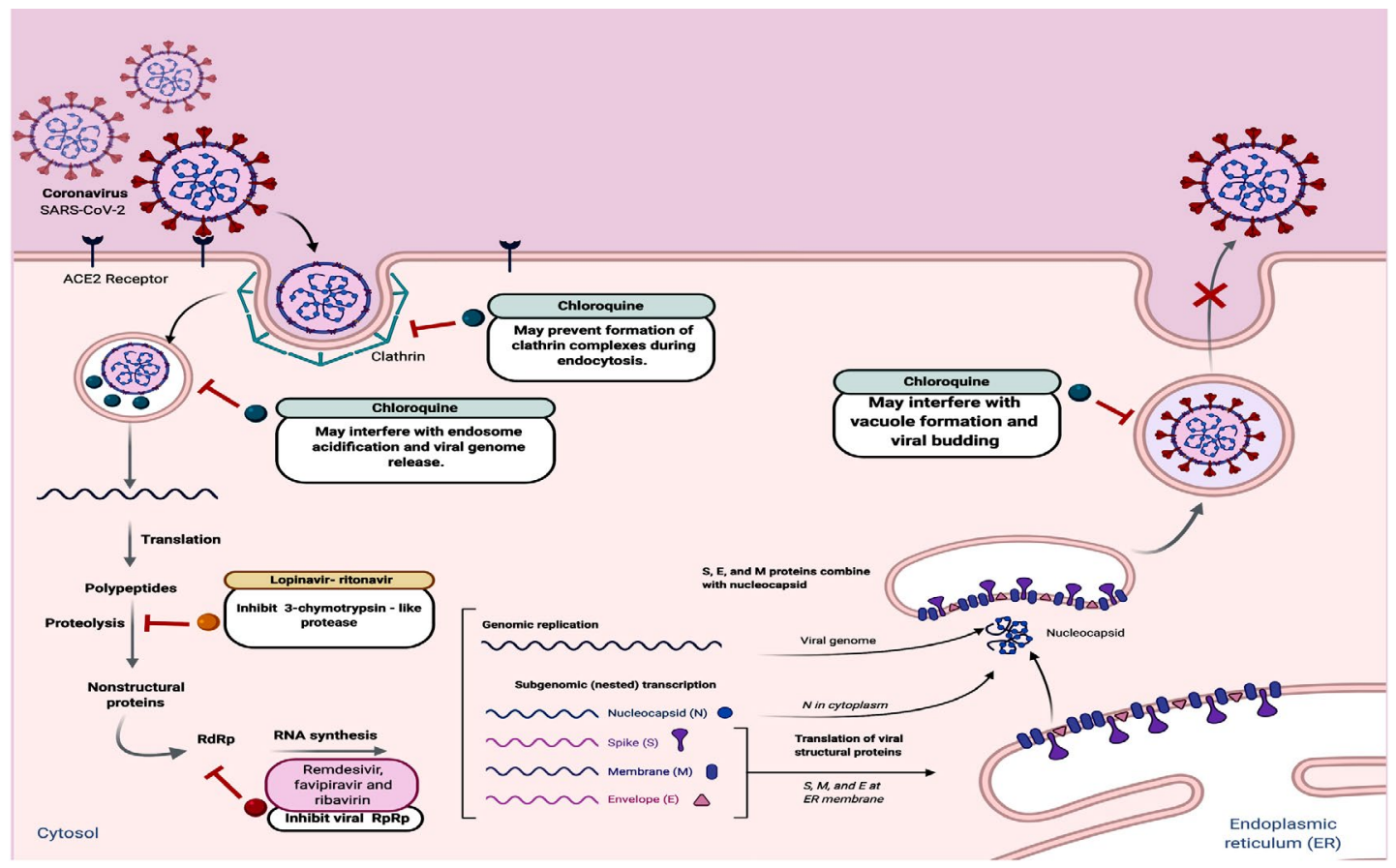

Fig. 4. Potential repositioned drug candidates for COVID-19 (Created by Biorender.com) 
to ACE2 receptor and then virus replication occurs. Replication of the virus results in cellular injury and release of proinflammatory signals. Additionally, virus binding to ACE2 results in increase in the level of local angiotensin-II, which results in vasoconstriction, endothelial activation, and proinflammatory cytokine release, causing damage for alveolar epithelial and vascular endothelial cells. Endothelial cell involvement may then spread across the vascularity of different organs ${ }^{63}$.

\section{COVID-19 and diabetic nephropathy}

Nearly $25 \%$ of patients with T2D are affected by diabetic nephropathy, which is considered as main cause of end-stage renal disease. Additionally, diabetic nephropathy is associated with elevated cardiovascular risk ${ }^{75}$. Despite acute respiratory failure being main feature of COVID-19; it was found out that other organs affection might occur. Following SARSCoV-2 infection of lungs, the virus may reach the circulation and then the kidney, causing renal cells injury. In a Chinese study, around $7 \%$ of patients infected with SARS-CoV suffered from acute kidney injury $^{75}$. For this reason, knowing how the kidney is affected by SARS-CoV-2 is urgently needed. More than $40 \%$ of hospitalized COVID-19 patients developed kidney disease, which was linked with greater hospital mortality. Some patients with COVID-19 had a pre-existing chronic kidney disease, which makes it a possible justification of the high pervasiveness of kidney involvement at hospital admission. Such patients have a proinflammatory state with functional defects in immune cell and may develop upper respiratory tract infection and pneumonia more favorably ${ }^{76}$.

Impact of both anti-diabetic treatments on COVID-19 outcomes, as well as therapeutic approaches for COVID-19 on management of diabetes requires further study.

Management of COVID-19 in diabetic patients

Diabetic patients have more risk for CoVs infection and mortality, this may be due to the poor glycemic control, which increases risk for secondary infection ${ }^{77}$. Combined with the latest guidelines of washing hands, social distancing and lockdown, good glycemic control help in reducing the risk for infection and even severity of the disease ${ }^{78,79}$. No specific treatment is approved for COVID-19 and only symptomatic and supportive treatment are applied ${ }^{17,80}$. Therefore, development of effective vaccine and specific antiviral treatment is the ultimate aim to fight $\mathrm{CoVs}^{81-89}$.

Nowadays, medical institutions and companies are recruited to design and produce effective vaccines for COVID-19 using whole virus (attenuated or inactivated) ${ }^{90-92}$, plasmid encoding viral antigens ${ }^{93,94}$ or viral proteins ${ }^{95-99}$. On 2020, several promising vaccine candidates have entered clinical phase such as Ad5-nCoV from CanSino Biologics (NCT04313127) ${ }^{28}$, INO-4800 from Inovio (NCT04336410) $^{100}$, PiCoVacc from Sinovac Biotech, mRNA-1273 from Moderna (NCT04299724) ${ }^{101}$, LVSMENP-DC (NCT04299724) and pathogen-specific aAPC (NCT04276896) from Shenzhen Medical Institute.

Moreover, repositioning of drugs is fast option to find clinically effective agents against COVID-19. Several approved antiviral drugs (Fig. 4) were re-tested against COVID-19 such as remdesivir, favipiravir, ribavirin ${ }^{81-88}$, lopinavirritonavir and chloroquine ${ }^{81,89,102-107}$. Despite their potential ability to inhibit viral replication, these repositioned drugs might show adverse effects with diabetic patients and overall outcomes have not yet been fully evaluated.

The low-cost proven antimalarial drugs, chloroquine and its derivative hydroxychloroquine, are tested clinically against COVID-19 and showed promising efficacy and safety ${ }^{81,89,102-108}$. Chloroquine acts via several mechanisms such as preventing endosomal acidification, inhibiting virus-host cells fusion/replication, interfering glycosylation of cellular receptors and inhibition of MAP-kinase altering virus assembly and budding $81,89,109-110$. Chloroquine has hypoglycemic effects and has been approved for diabetes since $2014^{65,111}$. This hypoglycemic effect could be attributed to improvement of insulin sensitivity, increase of insulin secretion, reduction of hepatic insulin clearance and reduction of systemic inflammation $^{112}$. Therefore, diabetic patients infected with SARS-CoV-2 should be monitored for hypoglycaemia during and even after the use of chloroquine with other anti-hyperglycaemic $\operatorname{drugs}^{111,113}$.

However, some studies revealed that clinical trials of hydroxychloroquine did not show significant improvement in hospitalized COVID-19 patients compared to standard approaches ${ }^{114,115}$. 
Additionally, several adverse effects were reported with high doses of chloroquine with severe COVID-19 cases as well as life-threatening arrhythmias was reported when chloroquine is coadministered with azithromycin ${ }^{116}$. World Health Organization (WHO) has recently declared an official statement to prevent further clinical trial testing chloroquine and hydroxychloroquine on COVID-19 patients.

Corticosteroids could be used in COVID-19 for management of ARDS and sepsis, but they would negatively affect the glycemic levels.

\section{Effect of diabetes treatment on COVID-19}

The effect of oral anti-hyperglycemic drugs on the severity of COVID-19 is not fully studied. However, metformin and sodium glucose cotransporter (SGLT) inhibitors increase risk of lactic acidosis and should be stopped in sever ill patient with hemodynamic instability. Additionally, SGLT inhibitors (such as gliflozins) might result in over expression of ACE2 receptors, increasing risk of diabetic patients to have more complications if infected with SARS-CoV-2 (111). Therefore, SGLT2 inhibitors, which are used in management of T2D, may exacerbate the clinical outcomes of COVID-19. Sulfonylureas are effective in diabetes treatment but there is an increased risk of hypoglycemia in patients with irregular food intake ${ }^{64}$. Thiazolidinediones and glucagon-like peptide-1 agonists increase levels of ACE2 proteins ${ }^{117,118}$. Increasing ACE2 expression may not increase the entry of SARS-CoV-2 into host cells and this is because virus binding is also dependent on availability of transmembrane protease serine 2 (TMPRRS2) ${ }^{119}$. Thiazolidinediones is not recommended with COVID-19 patients due to risk of fluid retention and heart failure.

Although, insulin increases the expression of ACE2 protein via attenuation of disintegrin and metalloprotease effect, it is still the first choice to adjust blood sugar in hospitalized COVID-19 patients, especially patients in the intensive care units ${ }^{120}$. Patients with mild COVID-19 can normally use their anti-hyperglycaemic drugs as long as they have mild infection and with normal oral intake ${ }^{77}$. On other hand, dipeptidyl peptidase 4 (DPP4) inhibitors, which are used for oral management of T2D, may have advantages in treatment of COVID-19 ${ }^{121}$. DPP4 is a serine exopeptidase receptor expressed ubiquitously in many organs and tissues such as lung, liver and kidney and has increased activity in T2D. DPP4 is the main entry receptor for MERS-CoVs and some studies described DPP4 as a co-receptor for SARS-CoV-2 entry ${ }^{121,122}$. DPP4 inactivates glucagon like peptide1 (GLP-1) and gastric inhibitory polypeptide (GIP), which are responsible for stimulation of insulin release and inhibition of glucagon release so lowering blood glucose ${ }^{123}$. If DPP4 enhances entry of SARS-CoV-2, DPP4 inhibitors (such as teneligliptin, vildagliptin and saxagliptin) could be repurposed for treatment of COVID-19 patients with diabetes.

\section{Vaccines against COVID-19}

Several vaccines have been developed against CoVs either via exposing the human body to viral antigens or to neutralizing antibodies. There are now several vaccines that are in use. The first mass vaccination programme started in early December 2020 and as of and as of 15 February 2021, 175.3 million vaccine doses have been administered. At least 7 different vaccines ( 3 platforms) have been administered. WHO issued an Emergency Use Listing (EULs) for the Pfizer COVID-19 vaccine (BNT162b2) on 31 December 2020. On 15 February 2021, WHO issued EULs for two versions of the AstraZeneca/Oxford COVID-19 vaccine, manufactured by the Serum Institute of India and SKBio. WHO is on track to EUL other vaccine products through June $^{124,125}$.

\section{CONCLUSIONS}

Tremendous international efforts are carried out to contain COVID-19 pandemic, which caused by the newly emerged SARS-CoV-2. Since DM is associated with high risk for SARS-CoV-2 infection and mortality, special attention should be given for diabetic patients. Potential mechanisms, which increase susceptibility of diabetic patients to viral infection, include defects of innate and adaptive immunity, efficient virus entry, delayed viral clearance, decreased $T$ cell function and cytokine storm syndrome. Drugs of DM affect on the control of COVID-19 and vice versa, so, screening for (pre) diabetes in COVID-19 patients is critical as well as blood glucose monitoring and management during treatment of the infection.

\section{ACKNOWLEDGMENTS}

None. 


\section{CONFLICT OF INTEREST}

The authors declare that there is no conflict of interest.

\section{AUTHORS' CONTRIBUTION}

All authors listed have made a substantial, direct and intellectual contribution to the work, and approved it for publication.

\section{FUNDING}

None.

\section{DATA AVAILABILITY}

All datasets generated or analyzed during this study are included in the manuscript.

\section{ETHICS STATEMENT}

Not applicable.

\section{REFERENCES}

1. Abd Ellah NH, Gad SF, Muhammad K, Batiha GE, Hetta HF. Nanomedicine as a promising approach for diagnosis, treatment and prophylaxis against COVID-19. Nanomedicine (London). 2020;15(21):20852102. doi: $10.2217 / \mathrm{nnm}-2020-0247$

2. Abdellatif $A A H$, Tawfeek HM, Abdelfattah A, Batiha GE-S, Hetta HF. Recent updates in COVID-19 with emphasis on inhalation therapeutics: nanostructured and targeting systems. J Drug Deliv Sci Technol. 2021;63:102435. doi: 10.1016/j.jddst.2021.102435

3. Abid SA, Suhail A, Al-Kadmy IM, et al. Biosensors as a future diagnostic approach for COVID-19. Life Sci. 2021;273:119117. doi: 10.1016/j.lfs.2021.119117

4. Dar HA, Waheed $Y$, Najmi MH, et al. Multiepitope Subunit Vaccine Design against COVID-19 Based on the Spike Protein of SARS-CoV-2: An In Silico Analysis. J Immunol Res. 2020;2020:8893483. doi: 10.1155/2020/8893483

5. Hetta H, Muhammad K, El-Masry E, et al. The interplay between vitamin $D$ and COVID-19: protective or bystander? Eur Rev Med Pharmacol Sci. 2021;25(4):2131-2145. doi: 10.26355/ eurrev_202102_25119

6. Kasozi KI, Niedbala G, Alqarni M, et al. Bee Venom-A Potential Complementary Medicine Candidate for SARS-CoV-2 Infections. Front Public Health. 2020;8:594458. doi: 10.3389/fpubh.2020.594458

7. Beshbishy AM, Hetta HF, Hussein DE, et al. Factors associated with increased morbidity and mortality of obese and overweight COVID-19 patients. Biology. 2020;9(9):280. doi: 10.3390/biology9090280

8. Mahmood Z, Alrefai $\mathrm{H}$, Hetta $\mathrm{HF}$, et al. Investigating virological, immunological, and pathological avenues to identify potential targets for developing covid-19 treatment and prevention strategies. Vaccines. 2020;8(3):443. doi: 10.3390/vaccines8030443

9. Li B, Yang J, Zhao F, et al. Prevalence and impact of cardiovascular metabolic diseases on COVID-19 in China. Clin Res Cardiol. 2020:109(5)531-538. doi: 10.1007/s00392-020-01626-9

10. Zhang J-j, Dong X, Cao Y-y, et al. Clinical characteristics of 140 patients infected with SARS-CoV-2 in Wuhan, China. Allergy. 2020;75(7):1730-1741. doi: 10.1111/ all.14238

11. Booth CM, Matukas LM, Tomlinson GA, et al. Clinical features and short-term outcomes of 144 patients with SARS in the greater Toronto area. JAMA. 2003;289(21):2801-2809. doi: 10.1001/jama.289.21. JOC30885

12. Muniyappa R, Gubbi S. COVID-19 pandemic, coronaviruses, and diabetes mellitus. Am J Physiol Endocrinol Metab. 2020;318(5):E736-E741. doi: 10.1152/ajpendo.00124.2020

13. Ahn D-G, Shin H-J, Kim M-H, et al. Current Status of Epidemiology, Diagnosis, Therapeutics, and Vaccines for Novel Coronavirus Disease 2019 (COVID-19). J Microbiol Biotechnol. 2020;30(3):313-324. doi: 10.4014/jmb.2003.03011

14. Loczechin A, Seron K, Barras A, et al. Functional Carbon Quantum Dots as Medical Countermeasures to Human Coronavirus. ACS Applied Materials \& Interfaces. 2019;11(46):42964-42974. doi: 10.1021/ acsami.9b15032

15. Centers for Disease Control and Prevention. accessed April 2020. https://phil.cdc.gov/Details. aspx?pid=23354.

16. An Overview of Nanotechnology Patents Focusing on Coronaviruses. NBIC+; Accessed on April 2020. https://statnano.com/news/67513/An-Overview-ofNanotechnology-Patents-Focusing-on-Coronaviruses.

17. Udugama B, Kadhiresan $\mathrm{P}$, Kozlowski HN, et al. Diagnosing COVID-19: The Disease and Tools for Detection. ACS Nano. 2020;14(4):3822-3835. doi: 10.1021/acsnano.0c02624

18. Lu R, Zhao X, Li J, et al. Genomic characterisation and epidemiology of 2019 novel coronavirus: implications for virus origins and receptor binding. The Lancet. 2020;395(10224):565-574. doi: 10.1016/S01406736(20)30251-8

19. Wu F, Zhao $S, Y u B$, et al. A new coronavirus associated with human respiratory disease in China. Nature. 2020;579(7798):265-269. doi: 10.1038/s41586-0202008-3

20. Khailany RA, Safdar M, Ozaslan M. Genomic characterization of a novel SARS-CoV-2. Gene Rep. 2020:19;100682. doi: 10.1016/j.genrep.2020.100682

21. Fehr AR, Perlman S. Coronaviruses: an overview of their replication and pathogenesis. Methods Mol Biol. 2015:1282;1-23. doi: 10.1007/978-1-4939-2438-7_1

22. Barcena M, Oostergetel GT, Bartelink W, et al. Cryoelectron tomography of mouse hepatitis virus: Insights into the structure of the coronavirion. Proc Natl Acad Sci USA. 2009;106(2):582-587. doi: 10.1073/ pnas. 0805270106

23. Neuman BW, Adair BD, Yoshioka C, et al. Supramolecular architecture of severe acute respiratory syndrome coronavirus revealed by electron cryomicroscopy. J Virol. 2006;80(16):7918-7928. doi: 10.1128/JVI.0064506 
24. Song W, Gui M, Wang X, Xiang Y. Cryo-EM structure of the SARS coronavirus spike glycoprotein in complex with its host cell receptor ACE2. PLOS Pathogens. 2018;14(8):e1007236. doi: 10.1371/ journal.ppat.1007236

25. Wan Y, Shang J, Graham R, Baric RS, Li FJJov. Receptor recognition by the novel coronavirus from Wuhan: an analysis based on decade-long structural studies of SARS coronavirus. J Virol. 2020;94(7):e00127-20. doi: 10.1128/JVI.00127-20

26. Raj VS, Mou H, Smits SL, et al. Dipeptidyl peptidase 4 is a functional receptor for the emerging human coronavirus-EMC. Nature. 2013;495(7440):251-254. doi: $10.1038 /$ nature12005

27. Li W, Moore MJ, Vasilieva N, et al. Angiotensinconverting enzyme 2 is a functional receptor for the SARS coronavirus. Nature. 2003;426(6965):450-454. doi: 10.1038/nature02145

28. Zhou P, Yang X-L, Wang X-G, et al. A pneumonia outbreak associated with a new coronavirus of probable bat origin. Nature. 2020;579(7798):270-273. doi: 10.1038/s41586-020-2012-7

29. Andersen KG, Rambaut A, Lipkin WI, Holmes EC, Garry RF. The proximal origin of SARS-CoV-2. Nat Med. 2020;26(4):450-452. doi: 10.1038/s41591-020-0820-9

30. Imai $\mathrm{Y}$, Kuba K, Ohto-Nakanishi T, Penninger JMJCJ. Angiotensin-converting enzyme $2\left(\mathrm{ACE}_{2}\right)$ in disease pathogenesis. Circ J. 2010;74(3):405-410. doi: 10.1253/circj.CJ-10-0045

31. Huang C, Wang $Y$, Li X, et al. Clinical features of patients infected with 2019 novel coronavirus in Wuhan, China. The lancet. 2020;395(10223):497-506. doi: 10.1016/ S0140-6736(20)30183-5

32. Leng Z, Zhu R, Hou W, et al. Transplantation of ACE2mesenchymal stem cells improves the outcome of patients with COVID-19 pneumonia. Aging Dis. 2020;11(2):216-228. doi: 10.14336/AD.2020.0228

33. Guo W, Li M, Dong Y, et al. Diabetes is a risk factor for the progression and prognosis of COVID-19. Diabetes/ Metabolism Research and Reviews. 2020;36(7):e3319. doi: 10.1002/dmrr.3319

34. Yang J-K, Lin S-S, Ji X-J, Guo L-M. Binding of SARS coronavirus to its receptor damages islets and causes acute diabetes. Acta diabetologica. 2010;47(3):193199. doi: 10.1007/s00592-009-0109-4

35. Ji H-L, Zhao R, Matalon S, Matthay MA. Elevated plasmin (ogen) as a common risk factor for COVID-19 susceptibility. Physiol Rev. 2020;100(3):1065-1075. doi: 10.1152/physrev.00013.2020

36. Ceccarelli M, Berretta M, Rullo EV, Nunnari G, Cacopardo B. Differences and similarities between Severe Acute Respiratory Syndrome (SARS)-CoronaVirus (CoV) and SARS-CoV-2. Would a rose by another name smell as sweet. Eur Rev Med Pharmacol Sci. 2020;24:27812783. doi: 10.26355/eurrev_202003_20551

37. Ai T, Yang Z, Hou H, et al. Correlation of Chest CT and RT-PCR Testing in Coronavirus Disease 2019 (COVID-19) in China: A Report of 1014 Cases. Radiology. 2020;296(2):E32-40. doi: 10.1148/ radiol.2020200642

38. Giacomelli A, Pezzati L, Conti F, et al. Self-reported Olfactory and Taste Disorders in Patients With Severe
Acute Respiratory Coronavirus 2 Infection: A Crosssectional Study. Clin Infect Dis. 2020;71(15):889-890. doi: 10.1093/cid/ciaa330

39. Wang D, Hu B, Hu C, et al. Clinical Characteristics of 138 Hospitalized Patients With 2019 Novel Coronavirus-Infected Pneumonia in Wuhan, China. JAMA. 2020;323(11):1061-1069. doi: 10.1001/ jama.2020.1585

40. Atluri S, Manchikanti L, Hirsch JA. Expanded Umbilical Cord Mesenchymal Stem Cells (UC-MSCs) as a Therapeutic Strategy in Managing Critically III COVID-19 Patients: The Case for Compassionate Use. Pain Physician. 2020;23(2):E71-E83.

41. Orioli L, Hermans MP, Thissen J-P, Maiter D, Vandeleene B, Yombi J-C. COVID-19 in diabetic patients: related risks and specifics of management. Ann Endocrinol. 2020;81(2-3):101-109. doi: 10.1016/j.ando.2020.05.001

42. Wu C, Chen X, Cai Y, et al. Risk Factors Associated With Acute Respiratory Distress Syndrome and Death in Patients With Coronavirus Disease 2019 Pneumonia in Wuhan, China. JAMA Intern Med. 2020;180(7):934-943. doi: 10.1001/jamainternmed.2020.0994

43. Fernandez C, Rysa J, Almgren $\mathrm{P}$, et al. Plasma levels of the proprotein convertase furin and incidence of diabetes and mortality. J Intern Med. 2018;284(4):377387. doi: 10.1111/joim.12783

44. Nyambuya TM, Dludla PV, Mxinwa V, Nkambule BB. T-cell activation and cardiovascular risk in adults with type 2 diabetes mellitus: A systematic review and meta-analysis. Clin Immunol. 2020;210:108313. doi: 10.1016/j.clim.2019.108313

45. Yang JK, Feng Y, Yuan MY, et al. Plasma glucose levels and diabetes are independent predictors for mortality and morbidity in patients with SARS. Diabet Med. 2006;23(6):623-628. doi: 10.1111/j.14645491.2006.01861.x

46. Banik GR, Alqahtani AS, Booy R, Rashid H. Risk factors for severity and mortality in patients with MERS-CoV: Analysis of publicly available data from Saudi Arabia. Virol Sin. 2016;31(1):81-84. doi: 10.1007/s12250-0153679-z

47. Zhu L, She Z-G, Cheng X, et al. Association of blood glucose control and outcomes in patients with COVID-19 and pre-existing type 2 diabetes. Cell Metab. 2020;31(6):1068-1077. doi: 10.1016/j. cmet.2020.04.021

48. Wu Z, McGoogan JM. Characteristics of and important lessons from the coronavirus disease 2019 (COVID-19) outbreak in China: summary of a report of 72314 cases from the Chinese Center for Disease Control and Prevention. JAMA. 2020;323(13):1239-1242. doi: 10.1001/jama.2020.2648

49. Cao B, Wang $Y$, Wen D, et al. A Trial of LopinavirRitonavir in Adults Hospitalized with Severe Covid-19. N Eng/J Med. 2020;382(19):1787-1799. doi: 10.1056/ NEJMoa2001282

50. Yang J, Zheng Y, Gou X, et al. Prevalence of comorbidities in the novel Wuhan coronavirus (COVID-19) infection: a systematic review and meta-analysis. Int J Infect Dis. 2020;94:91-95. doi: 10.1016/j.ijid.2020.03.017

51. Targher G, Mantovani A, Wang X-B, et al. Patients 
with diabetes are at higher risk for severe illness from COVID-19. Diabetes Metab. 2020;46(4):335-337. doi: 10.1016/j.diabet.2020.05.001

52. Abdelwahab FA, Hassanein KM, Hetta HF, Abdelmalek MO, Zahran AM, El-Badawy O. Impact of deranged B cell subsets distribution in the development of HCVrelated cirrhosis and HCC in type two diabetes mellitus. Scientific Reports. 2020;10(1):20383. doi: 10.1038/ s41598-020-77416-0

53. Hetta HF, Elsherbiny NM, Eloseily EM, et al. Evaluation of the immune memory response to routine HBV vaccine in Egyptian patients with Type 1 diabetes. Future Virology. 2020;15(4):215-222. doi: 10.2217/ fvl-2019-0121

54. Hetta HF, Fahmy EM, Mohamed GA, et al. Does vitamin $D$ status correlate with insulin resistance in obese prediabetic patients? An Egyptian multicenter study. Diabetes Metab Syndr. 2019;13(5):2813-2817. doi: 10.1016/j.dsx.2019.07.043

55. HuY, Sun J, Dai Z, et al. Prevalence and severity of corona virus disease 2019 (COVID-19): A systematic review and meta-analysis. J Clin Virol. 2020;127:104371. doi: 10.1016/j.jcv.2020.104371

56. Ji H-L, Zhao R, Matalon S, Matthay MA. Elevated Plasmin(ogen) as a Common Risk Factor for COVID-19 Susceptibility. Physiol Rev. 2020;100(3):1065-1075. doi: 10.1152/physrev.00013.2020

57. lacobellis G. COVID-19 and diabetes: can DPP4 inhibition play a role? Diabetes Res Clin Pract. 2020;162:108125. doi: 10.1016/j.diabres.2020.108125

58. Hetta HF, Khairy H, Ismail S. Circulating IL17A and IFN-gamma serum levels in cirrhotic hepatitis $C$ virus infected patients with autoimmune thyroiditis. Int $J$ Curr Microbiol Appl Sci. 2017;6(3):1972-1983. doi: 10.20546/ijcmas.2017.603.225

59. Zahran AM, Sayed SK, Abd El Hafeez HA, Khalifa WA, Mohamed NA, Hetta HF. Circulating microparticle subpopulation in metabolic syndrome: relation to oxidative stress and coagulation markers. Diabetes, Metab Syndr Obes. 2019;12:485-493. doi: 10.2147/ DMSO.S191750

60. Hetta HF, Elkady A, Morsy KH, Mohamed IS, Ibrahim MA. Serum level of IL17a among cirrhotic hepatitis $C$ virus infected patients with incidence of diabetes mellitus. Egypt J Immunol. 2017;24(1):79-88.

61. Chance WW, Rhee C, Yilmaz C, et al. Diminished alveolar microvascular reserves in type 2 diabetes reflect systemic microangiopathy. Diabetes Care. 2008;31(8):1596-1601. doi: 10.2337/dc07-2323

62. Kohio HP, Adamson AL. Glycolytic control of vacuolartype ATPase activity: A mechanism to regulate influenza viral infection. Virology. 2013;444(1-2):301309. doi: 10.1016/j.virol.2013.06.026

63. Whyte MB, Vas P, Heiss C, Feher MD. The contribution of diabetic micro-angiopathy to adverse outcomes in COVID-19. Diabetes Res Clin Pract. 2020;164:108217. doi: 10.1016/j.diabres.2020.108217

64. Gupta R, Hussain A, Misra A. Diabetes and COVID-19: evidence, current status and unanswered research questions. Eur J Clin Nutr. 2020;74:864-870. doi: 10.1038/s41430-020-0652-1

65. Katulanda P, Dissanayake HA, Ranathunga I, et al.
Prevention and management of COVID-19 among patients with diabetes: an appraisal of the literature. Diabetologia. 2020;63(8):1440-1452. doi: 10.1007/ s00125-020-05164-x

66. Ozougwu J, Obimba K, Belonwu C, Unakalamba C. The pathogenesis and pathophysiology of type 1 and type 2 diabetes mellitus. Journal of Physiology and Pathophysiology. 2013;4(4):46-57. doi: 10.5897/ JPAP2013.0001

67. Saleh A, Anwar MM, Zayed AE, et al. Impact of Ginkgo biloba extract and magnetized water on the survival rate and functional capabilities of pancreatic $\beta$-cells in type 2 diabetic rat model. Diabetes Metab Syndr Obes. 2019;12:1339-1347. doi: 10.2147/DMSO.S209856

68. Abd Ellah NH, Ahmed EA, Abd-Ellatief RB, Ali MF, Zahran AM, Hetta HF. Metoclopramide nanoparticles modulate immune response in a diabetic rat model: association with regulatory $T$ cells and proinflammatory cytokines. Int J Nanomedince. 2019;14:2383-2395. doi: 10.2147/IJN.S196842

69. Hetta HF, Mohamed GA, Gaber MA, et al. Visfatin serum levels in obese type 2 diabetic patients: relation to proinflammatory cytokines and insulin resistance. Egypt J Immunol. 2018;25(2):141-151.

70. Tatti P, Tonolo G, Zanfardino A, lafusco D. Is it fair to hope that patients with Type 1 Diabetes (autoimmune) may be spared by the infection of Covid-19? Med Hypotheses. 2020;142:109795. doi: 10.1016/j.mehy.2020.109795

71. Khalaf FR, Fahmy HM, Ibrahim AK, et al. Does a diabetic retinopathy educational program raise awareness among elderly diabetic patients? Diabetes Metab Syndr Obes. 2019;12:1867-1875. doi: 10.2147/DMSO. S208072

72. Barrett EJ, Liu Z, Khamaisi M, et al. Diabetic microvascular disease: an endocrine society scientific statement. J Clin Endocrinol Metab. 2017;102(12):43434410. doi: 10.1210/jc.2017-01922

73. Gattinoni L, Coppola S, Cressoni M, Busana M, Rossi S, Chiumello D. Covid-19 does not lead to a "typical" acute respiratory distress syndrome. Am J Respir Crit Care Med. 2020;201(10):1299-1300. doi: 10.1164/ rccm.202003-0817LE

74. Ciceri F, Beretta L, Scandroglio AM, et al. Microvascular COVID-19 lung vessels obstructive thromboinflammatory syndrome (MicroCLOTS): an atypical acute respiratory distress syndrome working hypothesis. Crit Care Resusc. 2020;22(2):95-97.

75. Tziomalos K, Athyros VG. Diabetic nephropathy: new risk factors and improvements in diagnosis. Rev Diabet Stud. 2015;12(1-2):110-118. doi: 10.1900/ RDS.2015.12.110

76. Cheng $\mathrm{Y}$, Luo R, Wang $\mathrm{K}$, et al. Kidney disease is associated with in-hospital death of COVID-19 patients. medRxiv. 2020. doi: 10.1101/2020.02.18.20023242

77. Gentile S, Strollo F, Ceriello A. COVID-19 infection in Italian people with diabetes: lessons learned for our future (an experience to be used). Diabetes Res Clin Pract. 2020;162:108137. doi: 10.1016/j. diabres.2020.108137

78. Adams JG, Walls RM. Supporting the health care workforce during the COVID-19 global epidemic. 
JAMA. 2020;323(15):1439-1440. doi: 10.1001/ jama.2020.3972

79. Pal R, Bhansali A. COVID-19, diabetes mellitus and ACE2: the conundrum. Diabetes Res Clin Pract. 2020;162:108132. doi: 10.1016/j.diabres.2020.108132

80. Coleman CM, Frieman MB. Coronaviruses: important emerging human pathogens. J Virol. 2014;88(10):52095212. doi: 10.1128/JVI.03488-13

81. Ren $\mathrm{H}$, Yang $\mathrm{Y}$, Wang $\mathrm{F}$, et al. Association of the insulin resistance marker TyG index with the severity and mortality of COVID-19. Cardiovasc Diabetol. 2020;19(1):58. doi: 10.1186/s12933-020-01035-2

82. Holshue ML, DeBolt C, Lindquist $\mathrm{S}$, et al. First Case of 2019 Novel Coronavirus in the United States. N Engl J Med. 2020;382(10):929-936. doi: 10.1056/ NEJMoa2001191

83. Reina J. Remdesivir, the antiviral hope against SARS-CoV-2. Revista Espanola de Quimioterapia. 2020;33(3):176-179. doi: 10.37201/req/028.2020

84. Sheahan TP, Sims AC, Leist SR, et al. Comparative therapeutic efficacy of remdesivir and combination lopinavir, ritonavir, and interferon beta against MERSCoV. Nat communs. 2020;11(1):222. doi: 10.1038/ s41467-019-13940-6

85. Kruse RL. Therapeutic strategies in an outbreak scenario to treat the novel coronavirus originating in Wuhan, China. F1000Research. 2020;9:72. doi: 10.12688/f1000research.22211.2

86. Cascella M, Rajnik M, Cuomo A, Dulebohn SC, Di Napoli R. Features, evaluation and treatment coronavirus (COVID-19). StatPearls [Internet]: StatPearls Publishing; 2020.

87. Zumla A, Chan JFW, Azhar El, Hui DSC, Yuen K-Y. Coronaviruses - drug discovery and therapeutic options. Nat Rev Drug Discov. 2016;15(5):327-347. doi: 10.1038/nrd.2015.37

88. Al-Tawfiq JA, Momattin H, Dib J, Memish ZA. Ribavirin and interferon therapy in patients infected with the Middle East respiratory syndrome coronavirus: an observational study. Int J Infect Dis. 2014;20:42-46. doi: 10.1016/j.ijid.2013.12.003

89. Vincent MJ, Bergeron E, Benjannet S, et al. Chloroquine is a potent inhibitor of SARS coronavirus infection and spread. Virol J. 2005;2(1):69. doi: 10.1186/1743-422X2-69

90. Menachery VD, Gralinski LE, Mitchell HD, et al. Combination attenuation offers strategy for live attenuated coronavirus vaccines. J Virol. 2018;92(17):e00710-00718. doi: 10.1128/JVI.0071018

91. Graham RL, Deming DJ, Deming ME, Yount BL, Baric RS. Evaluation of a recombination-resistant coronavirus as a broadly applicable, rapidly implementable vaccine platform. Commun Biol. 2018;1(1):179. doi: 10.1038/ s42003-018-0175-7

92. Spruth $\mathrm{M}$, Kistner $\mathrm{O}$, Savidis-Dacho $\mathrm{H}$, et al. A doubleinactivated whole virus candidate SARS coronavirus vaccine stimulates neutralising and protective antibody responses. Vaccine. 2006;24(5):652-661. doi: 10.1016/j.vaccine.2005.08.055

93. Wang S-F, Tseng S-P, Yen C-H, et al. Antibody-dependent SARS coronavirus infection is mediated by antibodies against spike proteins. Biochem Biophys Res Commun. 2014;451(2):208-214. doi: 10.1016/j.bbrc.2014.07.090

94. Wan Y, Shang J, Sun S, et al. Molecular Mechanism for Antibody-Dependent Enhancement of Coronavirus Entry. J Virol. 2020;94(5):e02015-02019. doi: 10.1128/ JVI.02015-19

95. Graham RL, Donaldson Ef, Baric RS. A decade after SARS: strategies for controlling emerging coronaviruses. Nat Rev Microbiol. 2013;11(12):836848. doi: 10.1038/nrmicro3143

96. Okba NMA, Raj VS, Haagmans BL. Middle East respiratory syndrome coronavirus vaccines: current status and novel approaches. Curr Opin Microbiol. 2017;23:49-58. doi: 10.1016/j.coviro.2017.03.007

97. Sui J, Li W, Murakami A, et al. Potent neutralization of severe acute respiratory syndrome (SARS) coronavirus by a human $\mathrm{mAb}$ to $\mathrm{S} 1$ protein that blocks receptor association. Proceedings of the National Academy of Sciences. 2004;101(8):2536-2541. doi: 10.1073/ pnas.0307140101

98. Du L, He Y, Zhou Y, Liu S, Zheng BJ, Jiang S. The spike protein of SARS-CoV-a target for vaccine and therapeutic development. Nat Rev Microbiol. 2009;7(3):226-236. doi: 10.1038/nrmicro2090

99. Zakhartchouk AN, Sharon C, Satkunarajah M, et al. Immunogenicity of a receptor-binding domain of SARS coronavirus spike protein in mice: Implications for a subunit vaccine. Vaccine. 2007;25(1):136-143. doi: 10.1016/j.vaccine.2006.06.084

100. Smith TRF, Patel A, Ramos S, et al. Immunogenicity of a DNA vaccine candidate for COVID-19. Nat Commun. 2020;11(1):2601. doi: 10.1038/s41467-020-16505-0

101. Wang F, Kream RM, Stefano GB. An Evidence Based Perspective on mRNA-SARS-CoV-2 Vaccine Development. Medical Science Monitor. 2020;26:e924700. doi: 10.12659/MSM.924700

102. Savarino A, Di Trani L, Donatelli I, Cauda R, Cassone A. New insights into the antiviral effects of chloroquine. The Lancet Infect Dis. 2006;6(2):67-69. doi: 10.1016/ S1473-3099(06)70361-9

103. Yan Y, Zou Z, Sun Y, et al. Anti-malaria drug chloroquine is highly effective in treating avian influenza $A$ H5N1 virus infection in an animal model. Cell Res. 2013;23(2):300-302. doi: 10.1038/cr.2012.165

104. Rolain J-M, Colson P, Raoult D. Recycling of chloroquine and its hydroxyl analogue to face bacterial, fungal and viral infections in the 21st century. Int I Antimicrob Agents. 2007;30(4):297-308. doi: 10.1016/j. ijantimicag.2007.05.015

105. Zhang Y, Chen C, Zhu S, et al. Isolation of 2019$\mathrm{nCoV}$ from a stool specimen of a laboratoryconfirmed case of the coronavirus disease 2019 (COVID-19). China CDC Weekly. 2020;2(8):123-124. doi: 10.46234/ccdcw2020.033

106. Batiha GE-S, Zayed MA, Awad AA, et al. Management of SARS-CoV-2 Infection: Key Focus in Macrolides Efficacy for COVID-19. Frontiers in Medicine. 2021;8(293).

107. Colson P, Rolain J-M, Raoult D. Chloroquine for the 2019 novel coronavirus SARS-CoV-2. Int J Antimicrob Agents. 2020;55:105923. doi: 10.1016/j. ijantimicag.2020.105923

108. Gao J, Tian Z, Yang X. Breakthrough: Chloroquine 
phosphate has shown apparent efficacy in treatment of COVID-19 associated pneumonia in clinical studies. Biosci Trends. 2020;14(1):72-73. doi: 10.5582/ bst.2020.01047

109. Wang $M$, Cao R, Zhang $L$, et al. Remdesivir and chloroquine effectively inhibit the recently emerged novel coronavirus (2019-nCoV) in vitro. Cell Res. 2020;30(3):269-271. doi: 10.1038/s41422-020-0282-0

110. Shetty RM, Namachivayam A. Evidence for Chloroquine/Hydroxychloroquine in the Treatment of COVID-19. Indian J Crit Care Med. 2021;25(4):441452. doi:10.5005/jp-journals-10071-23773

111. Baretic M. Case report of chloroquine therapy and hypoglycaemia in type 1 diabetes: What should we have in mind during the COVID-19 pandemic? Diabetes Metab Syndr. 2020;14(4):355-356. doi: 10.1016/j. dsx.2020.04.014

112. Infante M, Ricordi C, Fabbri A. Antihyperglycemic properties of hydroxychloroquine in patients with diabetes: risks and benefits at the time of COVID-19 pandemic. Journal of Diabetes. 2020;12(9):659-667. doi: 10.1111/1753-0407.13053

113. Mortensen EM, Leykum L, Nakashima B, Restrepo MI, Garcia S, Anzueto A. Association of hypoglycemia with mortality for subjects hospitalized with pneumonia. Am J Med Sci. 2010;339(3):239-243. doi: 10.1097/ MAJ.0b013e3181ca43fe

114. Tang W, Cao Z, Han M, et al. Hydroxychloroquine in patients with mainly mild to moderate coronavirus disease 2019: open label, randomised controlled trial. BMJ. 2020;369:m1849. doi: 10.1136/bmj.m1849

115. Chen J, Liu D, Liu L, et al. [A pilot study of hydroxychloroquine in treatment of patients with moderate COVID-19]. Zhejiang da xue xue bao. Yi xue ban = Journal of Zhejiang University. Medical sciences. 2020;49(2):215-219.

116. Borba MGS, Val FFA, Sampaio VS, et al. Effect of high vs low doses of chloroquine diphosphate as adjunctive therapy for patients hospitalized with severe acute respiratory syndrome coronavirus 2 (SARS-CoV-2) infection: a randomized clinical trial. JAMA Netw Open. 2020;3(4):e208857. doi: 10.1001/jamanetworkopen.2020.8857

117. Zhang $\mathrm{W}, \mathrm{Xu}$ Y-Z, Liu B, et al. Pioglitazone upregulates angiotensin converting enzyme 2 expression in insulin-sensitive tissues in rats with high-fat diet-induced nonalcoholic steatohepatitis. The Scientific World Journal. 2014;2014:603409. doi: $10.1155 / 2014 / 603409$

118. Romani-Perez $\mathrm{M}$, Outeirino-Iglesias $\mathrm{V}$, Moya $\mathrm{CM}$, et al. Activation of the GLP-1 receptor by liraglutide increases ACE2 expression, reversing right ventricle hypertrophy, and improving the production of SP-A and SP-B in the lungs of type 1 diabetes rats. Endocrinology. 2015;156(10):3559-3569. doi: 10.1210/en.2014-1685

119. Yang W, Cai X, Han X, Ji L. DPP-4 inhibitors and risk of infections: a meta-analysis of randomized controlled trials. Diabetes Metab Res Rev. 2016;32(4):391-404. doi: 10.1002/dmrr.2723

120. Salem ES, Grobe N, Elased KM. Insulin treatment attenuates renal ADAM17 and ACE2 shedding in diabetic Akita mice. Am J Physiol Renal Physiol. 2014;306(6):F629-F639. doi: 10.1152/ ajprenal.00516.2013

121. Strollo R, Pozzilli P. DPP4 inhibition: preventing SARSCoV-2 infection and/or progression of COVID-19? Diabetes Metab Res Rev. 2020;36(8):e3330. doi: 10.1002/dmrr.3330

122. Kushwaha RN, Haq W, Katti SB. Sixteen-years of clinically relevant dipeptidyl peptidase-IV (DPPIV) inhibitors for treatment of type-2 diabetes: a perspective. Curr Med Chem. 2014;21(35):4013-4045. doi: 10.2174/0929867321666140915143309

123. Gallwitz B. Clinical Use of DPP-4 Inhibitors. Front Endocrinol. 2019;10:389. doi: 10.3389/ fendo.2019.00389

124. Bilal M, Iqbal HMN. Recent advances in therapeutic modalities and vaccines to counter COVID-19/SARSCoV-2. Hum Vaccin Immunother. 2020;16(12):30343042. doi: 10.1080/21645515.2020.1794685

125. WHO. https://www.who.int/news-room/q-a-detail/ coronavirus-disease-(covid-19)-vaccines 